\title{
Wireless Carriers' Exclusive Handset Arrangements: an Empirical Look at the iPhone
}

\author{
Ting Zhu $\cdot$ Hongju Liu $•$ Pradeep K. Chintagunta
}

Published online: 27 February 2015

(C) Springer Science+Business Media New York 2015

\begin{abstract}
Since the Apple iPhone's launch in 2007 in an exclusive arrangement with AT\&T, it has garnered overwhelmingly positive responses from consumers and from the media. With its success, exclusive contracts between handset makers and wireless carriers have come under increasing scrutiny by regulators and lawmakers. Such practices have been criticized by regulators, by the media, and by "locked-out" consumers, due to the fact that a consumer has to subscribe to a particular service provider if he or she strongly prefers one handset to others. In this paper, we empirically examine the impact of handset exclusivity arrangements on consumer welfare. First we study consumers' purchase decisions for mobile services that include the choice of a handset and of a service provider. We do so by combining panel data on consumers' purchase decisions with supplemented data on prices and features of common handsets. Next, assuming a Stackelberg leader-follower relationship between the handset manufacturers and the service providers, and using our demand estimates, we recover the markups for the players in the market. We then simulate what would have happened in the counterfactual scenario when the iPhone is available from all carriers. Our results suggest that, if we take into account adjustments in handset prices from handset manufacturers and service providers in response to the change in market structure, consumer welfare will increase by $\$ 326$ million without the exclusive arrange-
\end{abstract}

T. Zhu $(\bowtie)$

Sauder School of Business, University of British Columbia,

Vancouver, BC, Canada

e-mail: ting.zhu@sauder.ubc.ca

H. Liu

School of Business, University of Connecticut, Storrs, CT, USA

e-mail: hliu@business.uconn.edu

P. K. Chintagunta

Booth School of Business, University of Chicago, Chicago, IL, USA

e-mail: pradeep.chintagunta@chicagobooth.edu ment. We view our analysis as a starting point to a more complete characterization of consumer behavior and the complex relationships among players in this industry.

Keywords Exclusive Arrangement · Distribution Channels · Wireless Service

JEL Classification L13 $\cdot$ L25 $\cdot$ L42 $\cdot$ L96

\section{Introduction}

The Apple iPhone was launched in 2007 under an exclusive distribution agreement with AT\&T. The exclusive agreement had lasted for four years before iPhone became available to Verizon customers in February 2011[1]. ${ }^{1}$ Apple and AT\&T activated two million units of the device in six months after its initial launch (Kharif and Burrows [2]). Due to the overwhelming success of the iPhone, exclusive contracts between handset makers and wireless carriers have drawn increasing scrutiny from lawmakers and regulators. For example, the Senate Commerce Committee held a hearing in 2009 on the subject of competition in the wireless industry, and urged the FCC to investigate whether such exclusive contracts are harming consumers by precluding consumers' handset access[3]. ${ }^{2}$ Further, the legal literature has seen a big debate on whether Carterfone type regulations that were enacted by the FCC in 1968 should also be brought to bear on the wireless market (see e.g. Ford et al. [4], Hoeker [5], Hahn and Singer[6]). These regulations forced "the separation of the sales of wireline telephone service from equipment and

\footnotetext{
1 "Verizon Unwraps iPhone," by Shayndi Raice and Yukari Iwatani Kane, Wall Street Journal, January 12, 2011.

2 "FCC to Review Exclusive Deals that Lock up Hot Cellphones," by Amy Schatz, Wall Street Journal, June 19, 2009, page B3.
} 
provided consumers the freedom to attach non-harmful thirdparty devices to the telephone network" (Hoeker [5]). ${ }^{3}$

Exclusive agreements typically allow a wireless carrier to serve as the sole distributor of a particular handset for a given period of time. Because most consumers in the U.S. purchase handsets in a bundle with a two-year service contract from a wireless carrier, the availability of handsets can significantly influence consumers' choice of wireless carriers. ${ }^{4}$ Thus wireless carriers can use an exclusive handset as a competitive differentiator to attract more consumers (Subramanian et al.[7]). For example, in the first quarter of 2009, $23 \%$ of the new AT\&T subscribers signed up for "a phone not offered by my carrier" (i.e., for the iPhone), and the company has reported that $40 \%$ of its iPhone customers switched from other services[8]. ${ }^{5}$

Large wireless carriers such as Verizon and AT\&T, who are more likely to benefit from these exclusive deals, have opposed any efforts to stop the practice. They argue that the deals encourage innovation and competition among handset manufacturers. However, smaller carriers such as U.S. Cellular ${ }^{6}$ and consumer groups such as Rural Cellular Association ${ }^{7}$ have complained about such deals, arguing that an exclusive arrangement hurts competition and prevents residents of rural areas from getting access to the latest technologies.

Scholars and researchers have offered a diverse range of views on the regulation of exclusive arrangements. For instance, Baker [9] criticized exclusive arrangements since they limit options for consumers and diminish the ability of smaller carriers to compete. Exclusive deals deprive some consumers of either their desired handsets, or their desired carriers, or both. On the other hand, Hahn and Singer [6] suggested that the practice encourages carriers to share the risk of launching a new handset; aligns the incentives of carriers with handset makers to provide high-quality services; and drives innovations by handset makers as they are able to share the costs of innovating with the service providers. Therefore exclusive arrangements can promote consumer welfare, and should be applauded by the government.

Despite the importance of understanding the welfare consequences of such exclusive deals, empirical evidence on

\footnotetext{
3 This regulation is viewed by many as a watershed event that eventually led to the breakup of AT\&T.

${ }^{4}$ According to Global Wireless Matrix 2007Q4, a study conducted by Merrill Lynch, the wireless penetration rate in the U.S was $84.4 \%$, including $16.1 \%$ prepaid customers and the rest on long term contracts. In our data $70 \%$ of consumers chose a two-year service contract.

5 "Is Handset Exclusivity Really the Wireless Issue of the Day?" by Roger Entner, Nielsen Wire, August 27, 2009.

${ }^{6}$ See the written statement of Mr. John E. Rooney, President and CEO, U.S. Cellular Corporation, before the U.S. Senate Committee on Commerce, Science and Transportation, June 17, 2009.

${ }^{7}$ See Rural Cellular Association's "Petition for Rulemaking Regarding Exclusivity Arrangements between Commercial Wireless Carriers and Handset Manufacturers" before the Federal Communications Commission.
}

these types of arrangements has been lacking. Specifically, while legal scholars have weighed in on both sides of the "Carterfone for wireless" debate, their arguments have been based largely on either what happened as a consequence of Carterfone or how the characteristics of the wireless market are different from those of the wired telephone market in the 1960s. Further, some authors (see Ford et al.[4], Hermalin and Katz[10]) have written out analytical models of the consequences of exclusive arrangements. For example, Ford et al. [4] show that handset prices would rise and service prices would remain unchanged if Carterfone type regulations are instituted for the wireless market. This seems to indicate that consumers will be worse off due to regulatory intervention.

Our objective in this paper is to empirically measure the impact of handset exclusivity arrangements on consumer welfare. Achieving this objective however, is a challenging task for a variety of reasons. In order to measure the welfare impact we need an appropriately specified consumer demand model that reflects the complexities of the cellphone handset-service marketplace. Further, we need to appropriately characterize how prices could change under the counterfactual of no-exclusivity. For this we need to specify the objectives of the various players in the market and the nature of interactions among them. Specifying the consumer demand model is complicated by the following: (a) the durable nature of the handset; (b) the large number of handset options available to subscribers; (c) the largely contractual nature of the relationship between the service provider and the customer; (d) variation across geographic markets of the service quality of various service providers. Further, in order to appropriately capture the potentially rich substitution patterns among handset and service providers, it would be preferable to have subscriberlevel handset purchase and subscription data.

Turning now to the supply side of the analysis, we note that the nature of the relationships, contracts and agreements among the handset manufacturers and the service providers are largely unobserved and the nature of transfer payments to the handset providers is unknown to us. Consequently, on both demand and supply sides we will need to make several simplifying assumptions that we describe next. Thus our study needs to be construed, at best, as a first step in understanding an otherwise complex problem. At the same time, we feel that even a first step can contribute to the limited empirical research in this area.

For demand estimation, we use Forrester Research's Consumer Technographics survey data from 2007 and 2008 when AT\&T was the only carrier for iPhone. Due to the overlap in survey respondents from year to year, we are able to carve out a panel from the two surveys (as have other researchers using these data). The data contain consumers' demographic information, as well as their wireless service providers and their handset characteristics. Since our data include consumers who did not have wireless service in 2007 but did so in 2008, we 
are able to account for possible category expansion. For those who had wireless service in 2007 , we model the purchase decisions of potential consumers only, i.e., those that are at the end of their contract period and are therefore "in the market" for wireless services in $2008 .{ }^{8}$ We construct consumers' choice sets by collecting the prices and features of the common handsets from Consumer Reports. Further, we collect data on the service quality of the different service providers in the different geographic markets. Together, these aspects of our data allow us to identify substitution patterns among the handset and service providers.

A challenge associated with our empirical task is how to handle the large number of choice alternatives. Because we define each choice alternative as a bundle of a handset and a service contract from a wireless carrier, the number of possible alternatives is even larger. To make the choice set manageable, we collect information on the common handset models from Consumer Reports, and aggregate over all other models. Note that if two handset models share very similar attributes, we treat them as the same alternative. In the end consumers' choice sets are constructed to include 88 different alternatives.

Using the above panel dataset assembled for the purpose, we first estimate a random coefficient logit model of consumer demand for wireless services that accounts for consumers' choices of both carriers and handsets. This demand function ignores the various dynamic aspects associated with the durable nature of the handset and service provision, i.e., we do not account for consumers' forward-looking expectations regarding, e.g., the availability and prices of handsets from providers, service quality (via the installation of more cellphone towers), etc. Although consumers treat the plan-handset decision as a "repeat" purchase made every 2 years (In 2009, 150 million handsets were sold to 270 million subscribers - an approximately $1: 2$ ratio; consistent with the 2 -year purchase cycle), this does not preclude consumers' forward-looking expectations regarding the plan-handset bundle. Nevertheless, it does make this category appear different from standard durable goods products such as automobiles and could potentially make it amenable to be approximated by myopic behavior. ${ }^{9}$ We learn about the demand function for wireless services from the observed choices made by customers and the price information for different handsets and service providers. We are particularly interested in consumers' intrinsic preferences for different handsets and service providers, the substitution patterns between handsets and across service providers and the state dependence in consumers' choices.

Next, we take the current prices of wireless service plans as given, and model the handset pricing decisions of handset

\footnotetext{
${ }^{8}$ Thus our analysis ignores the behavior of contract "breakers" and the role of the early termination fee. According to Sinkinson[21], less than $1.4 \%$ wireless subscribers report paying termination fees.

${ }^{9}$ Even in those markets, researchers have often assumed myopic consumers (e.g., Berry, Levinsohn and Pakes [34], Petrin [24], Sudhir [35]).
}

makers and wireless carriers as a Stackelberg leader-follower game, in which the handset manufacturers set wholesale prices first and the service providers then set prices for the handsets to the subscribers. A handset maker can charge different wholesale prices for the same handset model to different service providers. We then calculate the margins for handset manufacturers and for the wireless carriers on each handset. Here again, we ignore possible dynamic considerations on the supply side, the presence of long-term contracts between handset manufacturers and service providers, etc. Based on estimates for consumers' demand and firms' margins, we conduct counterfactual experiments to examine the welfare consequences of the exclusive contract between Apple and AT\&T vis-à-vis the iPhone. In particular we simulate what would have happened if the exclusive arrangement did not exist and hence the iPhone was available from all carriers. As a baseline for comparison, we first assume no competitive responses from other service providers and cell phone makers. Holding all prices constant, we find an annual welfare gain of \$210 million in the U.S. market. Next, since we would expect firms to set different wholesale and retail prices for handsets in the counterfactual market environment, we need to take into account the competitive responses in the market. After incorporating possible price adjustments according to our supply-side model, the annual welfare gain becomes $\$ 326$ million in the U.S. market.

An important question regarding our analysis is: how sensitive are our results to the assumptions we make on the demand and supply sides in terms of the dynamics and the nature of interactions between the various firms in the market. To accurately assess this we will need to, of course, explicitly relax these assumptions. An alternative would be to examine the degree to which key quantities of interest are likely to be incorrectly estimated by e.g., ignoring demand-side dynamics. For example, key factors that drive our counterfactual analysis are the estimates of preferences and price elasticities. We find that our price elasticity estimates for the iPhone are comparable to the estimates obtained by other economists who have detailed information on iPhone's profit margins. This gives us some assurance as to the validity of our estimates.

The remainder of this paper is organized as follows. In Section 2 we discuss the role of exclusive arrangement in the U.S. wireless market. Literature and data are described in section 3 and 4 respectively. We specify the demand model in Section 5. After a discussion of the estimation results in Section 6 , we present the counterfactual analysis and the welfare consequences of the exclusive arrangement on iPhone in Section 7. We conclude in Section 8.

\section{The U.S. Wireless Market}

Revenues in the U.S. wireless industry reached $\$ 145$ billion in 2008 after annual increases of over 10 percent since 2003 . The 
number of users was estimated to have exceeded 270 million cellular phone subscribers in the U.S. by the beginning of $2009^{10}$ and was the fastest growing sector among telecommunication services. The strong growth was attributed to improvements in the quality of wireless service and increases in the range of available features such as video content, e-mail and text messaging capabilities, and wireless Internet. Players in the wireless industry include device manufacturers (e.g. Nokia, Blackberry, Apple), wireless carriers (e.g. AT\&T, Verizon), broadband infrastructure companies (e.g. ClearWire, Qualcomm, Siemens, Ericsson), and application developers.

\subsection{Wireless Service Providers}

The wireless service market in the U.S. appears to be highly concentrated. In 2008, the four leading wireless service providers - AT\&T, Verizon Wireless, Sprint Nextel and T-Mobile USA (owned by German-based Deutsche Telekom) accounted for approximately 80 percent of the U.S. market (with the concentration ratio steadily increasing from $61 \%$ in 2003). Other wireless service providers include Alltel (now part of Verizon), U.S. Cellular and several more rural players. Notwithstanding these numbers, Merrill Lynch reports that in 2009, the concentration in the U.S. was the second lowest among the 26 countries under examination (Global Wireless Matrix 2Q09). And according to the 13th Commercial Mobile Radio Services Competition Report (FCC 2009), over $95 \%$ of the U.S. population lives in census blocks where there are 3 or more wireless service providers. Given this scenario, service providers compete on several dimensions coverage (including factors such as dropped calls), plan attributes (price, rollover minutes, free calling to other subscribers of the same provider), customer service quality, and quality of handsets. Service providers are aggressively working to attract new customers and to maintain current ones by improving coverage and service quality, fine tuning plan attributes to provide innovative services, and offering the latest handsets to their customers.

\subsection{Wireless Phones}

Demand for wireless phones in the U.S. increased 12 percent annually during 2003-2008 and reached 150 million units in 2008. It benefited from an increasing number of wireless service subscribers and decreasing wireless phone prices. In addition, continuous introductions of wireless phones with better design and more features had a strong influence on demand (FCC 2009).

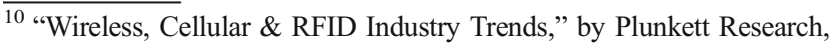
LTD.
}

Wireless phones were initially limited to one primary function - voice communication. Over time, manufacturers have added more and more features such as cameras, MP3 players and GPS systems. The introduction of "smartphones" was a major innovation in the wireless industry (Ford et al. 2008, Hahn and Singer 2009). Smartphones are cell phones that have many features of a desktop computer and are connected to the Internet. In addition to allowing people to make and receive calls and to check e-mails, smartphones run complete operating system software thereby providing a platform for application developers to write software for these platforms.

Although smartphones have been around for more than a decade, ${ }^{11}$ substantial growth only started in recent years. While early entrants included Nokia, Palm, BlackBerry, etc., that were popular with corporate customers, the launch of the iPhone was the most notable event in the consumer segment. Introduced in 2007, the iPhone accounted for a $10.8 \%$ share of the worldwide smartphone market by Q1 2009 with a total of 21 million units sold till January of that year. Because AT\&T was the sole distributor of iPhone under an exclusive deal, such exclusivity agreements have become a contentious issue (IDG news, 2009).

\subsection{Handset Exclusivity}

The four principal wireless carriers have been, over the years, able to tie up the most advanced, attractive handsets through exclusive arrangements. The negotiated handset exclusivity period is often several years or for the entire lifetime of the device. Handset technologies and features advance rapidly. According to Rooney [11].the average lifecycle of handsets is twelve months after initial launch. As a result, even an exclusive period of six months can impact the sales of that handset through other carriers greatly. While exclusivity was not always the norm, many of the recent iconic handsets were introduced under exclusive contracts. For example, The Sidekick was a T-Mobile exclusive in 2002; Motorola's Razr V3 was exclusively offered by AT\&T in 2004; the Blackberry Pearl was introduced in 2006 through T-Mobile only; Verizon was the exclusive distributor of the BlackBerry Storm; AT\&T was the exclusive distributor for the Blackberry Curve; and Sprint was the exclusive distributor of the Palm Pre. What is notable in this list is that the same handset provider (e.g. Blackberry) offers exclusive handsets to different service providers.

Although exclusive deals have been criticized by smaller rivals and consumer groups, the major carriers claim that such exclusive deals enable them to take risks on expensive new smartphones and bring them to market at discounted prices,

\footnotetext{
${ }^{11}$ An early example of a smartphone was the IBM Simon introduced in 1993. It was hailed as "the first time a company had placed a computer in a cellular phone" (Mobile Phone News, November 8, 1993).
} 
hence leading to more choices and lower prices for consumers. ${ }^{12}$ So AT\&T paid Apple $\$ 300$ per 8 GB iPhone 3G; Verizon paid Blackberry about $\$ 200$ per Storm; and Sprint paid Palm approximately $\$ 340$ per unit of the Palm Pre. Exclusive deals restrict handset manufacturers such as Palm, RIM and Apple from distributing their devices widely (i.e., by being exclusive to AT\&T, Apple only has access to about $30 \%$ of the U.S. market), but analysts point out that those companies benefit by getting a significant share of carriers' marketing and sales resources. ${ }^{13}$ For example, AT\&T's annual reports state that for the fiscal year 2007, increased sales and marketing costs of $\$ 572$ million, were attributable to the iPhone.

\section{Literature}

\subsection{The Wireless Industry}

Despite the dramatic changes in the wireless industry since the 1990s, the nature of the cellular phone market has not been explored in detail. One research stream examines the penetration of mobile services (e.g. Hausman[12]). Other studies analyze the market structure and competition between wireless service providers. For example, Iimi[13] analyzes the demand for wireless services using data on the Japanese market in late 1990 s, and finds that the service providers are highly differentiated. Bajari et al.[14] study the importance of national coverage to consumers' choices of service providers. Another stream of research investigates how users choose service plans under different pricing regimes (e.g. Lambrecht et al.[15]).

Most past studies have focused on consumers' choices of service providers, without taking into account their handset choices (e.g., Kim[16], Grzybowski and Pereira[17]). To our knowledge, there are four exceptions. Jain et al. [18] develops an analytical model to examine consumer subscription decisions based on prices of both cellular phones and service plans. In their framework the handset is assumed to be a homogenous product across service providers. Aribarg and Foutz [19] use a conjoint choice experiment to investigate consumers' decision process when they purchase a product bundle of a handset and a service plan. Sun [20] focuses on consumers' handset choices in smartphone markets without taking into account the impact of service providers. The closest study to our paper is Sinkinson [21]. He builds a consumer model for the demand side based on a "characteristics" approach where the stochasticity in choices from the researcher's perspective stems from the distribution of heterogeneity rather than from a logit error term. Then, he uses this demand model

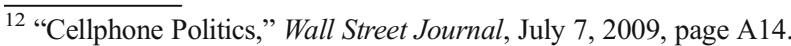

13 "Telecoms Face Antitrust Threat," by Amol Sharma, Wall Street Journal, July 7, 2009, page A1[36].
}

to analyze the Nash bargaining game played by Apple, Verzion and AT\&T for the supply side. His modeling approach has several appealing features; however like us he needs to make many simplifying assumptions for reasons of tractability. Given our objectives in this paper, we make a different set of assumptions, those that we believe are in line with our specific objectives. Ultimately, we view both these papers as having complementary goals.

\subsection{Vertical Restraints}

An exclusive contract requires a handset model to be sold by certain service providers. Such restrictions are referred to as vertical constraints by industrial organization economists. There is a large literature on the economic impact of such constraints (see e.g. Lafontaine and Slade[22]). Theoretical work has investigated the justification for and the consequences of exclusive contracts. In some cases such constraints can reduce economic welfare, whereas in other cases they may increase economic welfare. In particular, Subramanian et al. [7] examines when and why a cellular service provider and a handset manufacturer may decide to enter an exclusive contract. Their model suggests that the exclusive contract raises the rival service provider's handset costs by reducing the competition faced by a rival handset manufacturer. A service provider's benefit from an exclusive contract increases with the degree of service differentiation.

A number of empirical papers on channel structure also relate to this study (e.g. Besanko et al. [23], Chen et al. [24], Chu et al. 2007, Villas-Boas [25]. In particular Asker [26] evaluates the effect of exclusive arrangement on competition in the Chicago beer market. Brenkers and Verboven [27] study the competitive effects of liberalizing the selective and exclusive distribution system in the European automobile market. For our counterfactual analysis, our pricing model follows this stream of research and especially Asker [26], Chen et al.[24] and Villas-Boas[25].

\section{Data Description}

In this paper we study consumers' purchase decisions in mobile handsets and service providers. We use Forrester Research's Consumer Technographics survey data collected in early 2008 and 2009. The data reflect purchase information in 2007 and 2008 respectively. The survey goes out to about 60,000 consumers in the U.S. and Canada each year with some overlap in respondents across years. There are 10,546 consumers in the U.S. who participated in both 2008 and 2009. Among them we identify 7526 consumers who made a purchase decision in 2008, while others continued with the second year of their two-year contract. We have detailed information on household demographics, their attitudes towards 
technology, their mobile service providers, and characteristics of their handsets. ${ }^{14}$

Tables 1 and 2 summarize consumers' subscription decisions in 2007 and 2008. In Table 1, we compare the market share of leading handset manufacturers. It shows that the market share for smartphone brands such as Apple and BlackBerry increased in 2008. However, regular wireless phones still dominated the market. Table 2 describes consumers' switching patterns across service providers. The two leading carriers, AT\&T and Verizon, accounted for almost $50 \%$ of the market in 2008 . The table also shows s strong state dependence in choice of service providers. For example, 1378 out of 1669 AT\&T users in 2007 chose to stay with AT\&T in 2008. Note that these customers were at the end of their two-year contracts and could, in principle, have switched providers. Similar patterns can also be found for other service providers. Verizon has the lowest churn rate (15\%), and is followed by AT\&T at $17 \%$. Both Sprint and T-Mobile have higher churn rate at about $30 \%$. The data are consistent with the monthly churn rates reported by Merrill Lynch $-1.3 \%, 1.6 \%$, $2.3 \%$ and $2.7 \%$ for Verizon, AT\&T, Sprint and T-Mobile respectively (Global Wireless Matrix 2Q09).

Given consumers' brand switching behavior, we look for indications of any "iPhone effect" on consumer purchasing decisions including the choices of handsets and carriers. In Table 2, we observe that both AT\&T and Verizon had more service subscribers in 2008 than in 2007; AT\&T attracted more new subscribers than Verizon. We further look into the handset choices by AT\&T subscribers. Table 3 indicates that compared to existing AT\&T subscribers, those who switched from Verizon were more likely to purchase the iPhone. This seems to suggest that some Verizon customers switched to AT\&T for the iPhone. If a consumer preferred Verizon but had to switch because iPhone was only available through AT\&T, this would constitute a welfare loss caused by the exclusivity arrangements on iPhone. This observation also motivates the need to allow for heterogeneity in handset preferences for any service provider as well as heterogeneity in provider preferences for any given handset $-\mathrm{a}$ feature that we incorporate into our model.

To supplement our data, we obtain prices and features of the common handsets from Consumer Reports and CNET.com. Carriers subsidize handsets if they are purchased with a twoyear contract. For example, AT\&T paid Apple $\$ 300$ for an iPhone $3 \mathrm{G}$ (with 8GB storage), leaving AT\&T customers the balance of \$199. Verizon paid RIM roughly \$200 toward the \$399 total price of the BlackBerry Storm, leaving its customers the balance of $\$ 199$. Even lower-end phones can draw substantial subsidies from carriers. On the other hand, not everyone needs the sophisticated capabilities offered by a smartphone. The market is still dominated by regular cell phones. A regular

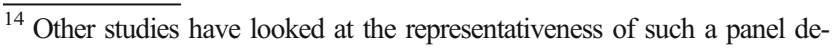
rived from repeated cross-sections of overlapping data (e.g., Liu et al. [20]).
}

Table 1 Summary of consumer handset purchase decisions

Note: Based on the survey responses from 10546 consumers

\begin{tabular}{llc}
\hline Brand & $2007(\%)$ & $2008(\%)$ \\
\hline Carrier's brand & 8.57 & 7.63 \\
Apple & 0.35 & 1.33 \\
BlackBerry & 1.69 & 3.89 \\
HTC & 0 & 0.34 \\
Kyocera & 2.34 & 1.96 \\
LG & 14.17 & 18.66 \\
Motorola & 26.13 & 23.51 \\
Nokia & 14.35 & 11.86 \\
Palm & 0.93 & 0.90 \\
Samsung & 12.03 & 13.43 \\
Sanyo & 2.57 & 1.81 \\
Sony Ericsson & 1.87 & 1.86 \\
Others & 2.35 & 2.26 \\
No phone & 12.68 & 10.56 \\
\hline
\end{tabular}

cell phone is usually priced less than $\$ 50$ and often free with a two-year contract. Figure 1 describes the distribution of handset prices to the end consumers.

The prices for carriers' service plans are collected from carriers' websites. For the same carrier, the service plans are essentially the same throughout the country. Therefore we assume that consumers in the U.S. face the same set of prices for wireless services, although the service quality varies across different areas for different service providers. To control for the effects of carriers' signal quality on consumers' choices, we collect data from www.signalmap.com, which records the signal strength for major wireless carriers reported by consumers throughout the country. The signal strength is reported on a scale from 1 to 5 . We calculate the average signal strength for each carrier in different designated market areas (DMAs), and then match the DMA information with the Forrester survey data on where respondents live. Table 4 shows the average signal strength for the four major carriers across markets. AT\&T and Verizon appear to provide stronger

Table 2 Summary of consumer service subscription decisions

\begin{tabular}{llllllll}
\hline & None & AT\&T & Sprint & T-Mobile & Verizon & Others & $\begin{array}{l}\text { Total } \\
(2007)\end{array}$ \\
\hline None & 901 & 103 & 18 & 39 & 72 & 204 & 1337 \\
AT\&T & 54 & 1378 & 25 & 27 & 84 & 101 & 1669 \\
Sprint & 14 & 46 & 362 & 16 & 57 & 43 & 538 \\
T-Mobile & 15 & 38 & 11 & 363 & 49 & 33 & 509 \\
Verizon & 29 & 90 & 32 & 32 & 1425 & 67 & 1675 \\
Others & 101 & 227 & 72 & 50 & 143 & 1205 & 1789 \\
Total & 1114 & 1882 & 520 & 527 & 1830 & 1653 & 7526 \\
$\quad(2008)$ & & & & & & & \\
\hline
\end{tabular}

Note: The numbers in each row represent the number of subscribers in 2007. The numbers in each column represent the number of subscribers in 2008 
Table 3 Handset choices by AT\&T service subscribers in 2008

\begin{tabular}{lll}
\hline Brand & All subscribers & Subscribers from Verizon \\
\hline Apple & $5.7 \%$ & $12.2 \%$ \\
BlackBerry & 6.2 & 10.0 \\
HTC & 0.4 & 3.3 \\
LG & 12.2 & 10.0 \\
Motorola & 16.2 & 11.1 \\
Nokia & 18.4 & 17.8 \\
Palm & 0.7 & 1.1 \\
Samsung & 14.8 & 10.0 \\
Sanyo & 0.5 & 1.1 \\
Sony Ericsson & 6.1 & 4.4 \\
Others & 18.8 & 18.9 \\
Number of subscribers & 1882 & 90 \\
\hline
\end{tabular}

signals at lower variation across markets than Sprint and TMobile.

To illustrate the effect of signal quality on consumer choices, we compare consumers' subscription decisions across DMAs. In Table 5, we summarize consumers' carrier choice in markets where AT\&T offers superior signals, i.e., AT\&T's average signal strength $\geq 3$, whereas Verizon's average signal strength $\leq 2$. We find that AT\&T had a higher market share in these markets, and attracted more customers in 2008. On the other hand, in Table 6 we summarize consumers' carrier choices in markets where AT\&T offers inferior signals, i.e., AT\&T's average signal strength $\leq 2$, whereas Verizon's average signal strength $\geq 3$. We observe a higher market share and more recruits for Verizon in these markets.

\section{The Model}

We consider a market with competing service providers and their compatible handsets. We assume that consumers choose service providers and handsets simultaneously, and thus each choice alternative is a bundle of a handset and a two-year contract with a service provider. We assume that a smartphone

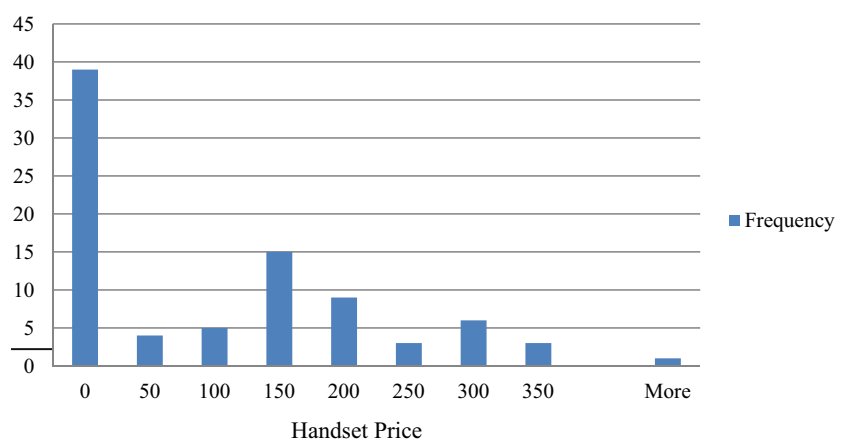

Fig. 1 Frequency distribution of handset prices
Table 4 Average signal strength by carrier

\begin{tabular}{lll}
\hline Carrier & $\begin{array}{l}\text { Average } \\
\text { strength }\end{array}$ & $\begin{array}{l}\text { Standard } \\
\text { deviation }\end{array}$ \\
\hline AT\&T & 2.63 & 0.92 \\
Sprint & 2.23 & 1.17 \\
T-Mobile & 2.29 & 1.16 \\
Verizon & 2.59 & 0.99 \\
\hline
\end{tabular}

purchase is always coupled with a corresponding data plan. The outside option consists of no purchase as well as the wireless service plans without a long term contract such as the prepaid plans. ${ }^{15}$

\subsection{Consumer Utility Specification}

The indirect utility function is defined over a handset and service plan bundle. If choosing handset $j$ and service provider $k$ at time $t$, a consumer $i$ obtains a utility of

$U_{i j k t}=V_{i j k t}+\varepsilon_{i j k t}$,

Where the deterministic component of utility is given by:

$$
\begin{aligned}
V_{i j k t}= & x_{j k t}{ }^{\prime} \lambda_{i}+\alpha_{i k}-\beta_{i}{ }^{H} p_{j k t}^{H}-\beta_{i}{ }^{S} p_{j k t}^{S}+\gamma_{H} I\left\{b_{i, t-1}=b_{j}\right\} \\
& +\gamma_{S} I\left\{s_{i, t-1}=k\right\}+\xi_{j k t}
\end{aligned}
$$

$j=1,2, \ldots, J ; \quad k=1,2, \ldots, K_{j}$

$J$ is the total number of handsets, including both smartphones and regular phones; and $K_{j}$ is the number of service providers that carry handset $j . x_{j k t}$ is a vector of handset characteristics, including the handset brand and indicator variables for regular phone, smartphone, touch screen, GPS, etc. The intrinsic preference for service provider $k$ is represented by $\alpha_{i k}$, which is assumed to vary across consumers. $p_{j k t}^{H}$ is the handset price and $p_{j k t}^{S}$ is the monthly service fee. We allow the price coefficient to be different across the two prices, because consumers are likely to treat the one-shot handset price and the monthly service price differently. ${ }^{16}$ If handset $j$ is a smart-

\footnotetext{
${ }^{15}$ Potentially we are able to estimate a model with two separate outside goods - a prepaid plan and no wireless service. Given the limited information about the prepaid plans in the data, we choose to combine these two options as one alternative in the choice set.

${ }^{16}$ Alternatively we can estimate a single price coefficient, but add up the handset price and the discounted flow of monthly service fees, with the discount factor to be estimated as well. In other words, $\beta_{i}{ }^{H} p_{j k t}^{H}+\beta_{i}{ }^{S} p_{j k t}^{S}$ $=\beta_{i}\left(p_{j k t}^{H}+\sum_{\tau=t}^{t+24} \rho_{i}^{\tau-t} p_{j k \tau}^{S}\right)$ to a scaling factor and so none of the other parameter estimates will change.
} 
Table 5 Wireless subscriptions in pro-AT\&T markets (AT\&T signal strength $\geq 3$ and Verizon signal strength $\leq 2$ )

\begin{tabular}{llllllll}
\hline & None & AT\&T & Sprint & T-Mobile & Verizon & Others & $\begin{array}{l}\text { Total } \\
(2007)\end{array}$ \\
\hline None & 261 & 32 & 1 & 13 & 14 & 55 & 276 \\
AT\&T & 15 & 365 & 6 & 11 & 24 & 23 & 444 \\
Sprint & 4 & 11 & 101 & 6 & 13 & 10 & 145 \\
T-Mobile & 3 & 14 & 4 & 143 & 18 & 15 & 197 \\
Verizon & 6 & 27 & 10 & 10 & 358 & 12 & 423 \\
Others & 27 & 72 & 18 & 20 & 38 & 342 & 517 \\
Total & 316 & 521 & 140 & 203 & 465 & 457 & 2102 \\
$\quad(2008)$ & & & & & & & \\
\hline
\end{tabular}

phone, then $p_{j k t}^{S}$ includes the monthly fee for the basic service as well as that for the data plan.

We use two indicator functions to control for potential state dependence in consumer choices of both handsets and service providers. $I\left\{b_{i, t-1}=b_{j}\right\}$ is an indicator function that equals to one if handset $j$ has the same brand as consumer $i$ 's previous handset and zero otherwise. Similarly $I\left\{s_{i, t-1}=k\right\}$ equals one if consumer $i$ chose $k$ as the service provider in the last period. $\xi_{j k t}$ represents other characteristics that are unobservable to the researcher but observed by consumers. Finally $\varepsilon_{i j k t}$ is a random error that follows a type 1 extreme value distribution.

We use a random coefficients logit model to allow for more flexible substitution patterns across choice alternatives. In particular, we allow certain parameters to vary across consumers according to

$$
\begin{aligned}
& {\left[\gamma_{i}^{\text {smart }}, \alpha_{i 1}, \alpha_{i 2}, \alpha_{i 3}, \alpha_{i 4}\right]^{\prime}=\left[\gamma^{\text {smart }}+\tau T e c h_{i}, \alpha_{1}, \alpha_{2}, \alpha_{3}, \alpha_{4}\right]} \\
& +v_{i}
\end{aligned}
$$

$\gamma^{\text {smart }}$ represents a consumer's preference toward smartphones, and $\alpha$ represents her preference toward wireless service providers with subscripts $1-4$ indicating AT\&T, Sprint, T-Mobile and Verizon respectively. The variable $T_{e c h}$ represents whether consumer $i$ likes technology or not, as

Table 6 Wireless subscriptions in pro-Verizon markets (AT\&T signal strength $\leq 2$ and Verizon signal strength $\geq 3$ )

\begin{tabular}{llllllll}
\hline & None & AT\&T & Sprint & T-Mobile & Verizon & Others & $\begin{array}{l}\text { Total } \\
(2007)\end{array}$ \\
\hline None & 147 & 12 & 4 & 5 & 10 & 42 & 220 \\
AT\&T & 4 & 193 & 1 & 3 & 11 & 19 & 231 \\
Sprint & 0 & 5 & 62 & 4 & 11 & 4 & 86 \\
T-Mobile & 2 & 4 & 1 & 45 & 3 & 6 & 61 \\
Verizon & 6 & 12 & 2 & 5 & 231 & 9 & 265 \\
Others & 20 & 28 & 8 & 8 & 30 & 310 & 302 \\
Total & 179 & 252 & 78 & 70 & 296 & 290 & 1165 \\
$\quad(2008)$ & & & & & & & \\
\hline
\end{tabular}

indicated in her responses to the Forrester survey. To allow for correlations between consumer preferences for smartphones and for service providers, we assume that $v_{i}$ follows a multivariate normal distribution with mean zero and with the following covariance matrix:

$\left[\begin{array}{ccccc}\sigma_{11} & \sigma_{12} & \sigma_{13} & \sigma_{14} & \sigma_{15} \\ \sigma_{12} & \sigma_{22} & 0 & 0 & 0 \\ \sigma_{13} & 0 & \sigma_{33} & 0 & 0 \\ \sigma_{14} & 0 & 0 & \sigma_{44} & 0 \\ \sigma_{15} & 0 & 0 & 0 & \sigma_{55}\end{array}\right]$

To reduce the number of parameters to be estimated we assume zero correlations between the preferences for different service providers.

\subsection{Identification}

Model identification heavily relies on the variation in prices and other characteristics of handsets. The brand preferences for different service providers are identified by the relative market share of the same handset across carriers. Similarly, the brand preferences for handsets are identified by the relative share of the different brands within a carrier after controlling for prices and product characteristics. State dependence can be identified from the extent of switching in the data; and the effects of signal quality off of variation across geographic markets.

\subsection{Estimation Issues}

In the utility specification for a handset and service plan bundle in Eq. (1), the handset prices can be correlated with the unobserved product characteristics, such as stylishness of design. If the resulting endogeneity is not controlled for our parameter estimates will be biased. Therefore we use the control function approach proposed by Petrin and Train [24] to address this issue. In the first stage we recover the unobserved attributes as a control factor by regressing handset prices on a set of observed exogenous and instrumental variables. In the second stage we estimate the demand parameters while using the recovered control factor as an extra variable.

Specifically in the first stage we recover $\xi_{j k t}$, a one-to-one mapping of $\xi_{j k t}$, through the following regression:

$p_{j k t}^{H}=\omega z_{j k t}+\xi_{j k t}{ }^{*}$

$z_{j k t}$ includes dummy variables for service providers and handset brands, exogenous handset characteristics, and a set of instrumental variables. Similar to Albuquerque and Bronnenberg [28], Petrin and Train[24] and Iimi [13], we use the following instruments: (28) the mean value of each exogenous characteristic across all other handsets of the same brand sold by the same service provider; (19) the mean value of each exogenous characteristic across all handsets of the 
same brand sold by other service providers; and (26) the mean value of each exogenous characteristic across all handsets of other brands sold by the same service provider.

\subsection{Likelihood Function}

Using the obtained $\xi_{j k t} *$ as a covariate in place of $\xi_{j k t}$ in Eq. (1), the estimation of demand parameters can proceed via maximizing the following likelihood function:

$L=\prod_{i} \int \prod_{k} \prod_{j} \mathrm{P}_{i j k t}\left(x, p, \xi, v_{i}\right)^{y_{i j k t}} f\left(v_{i}\right) d v_{i}$

$P_{i j k t}$ represents the probability that consumer $i$ chooses handset $j$ from carrier $k$ at time $t$, and $y_{i j k t}$ is an indicator variable that takes value 1 if that happens..

Because the second stage maximum likelihood estimation uses an estimated $\xi_{j k t}{ }^{*}$ from the first stage, the standard error of the second stage estimator has to be adjusted accordingly following Petrin and Train [29].

\subsection{Pricing Model}

In order to conduct counterfactual experiments to examine the welfare consequences of the exclusive contract between Apple and AT\&T vis-à-vis the iPhone, we need to simulate what would have happened if the exclusive arrangement did not exist and hence the iPhone was available from all carriers. Similar to Sun [30], we first model the handset pricing decisions of handset makers and wireless carriers as a Stackelberg leader-follower game, in which the handset manufacturers set wholesale prices first and the service providers then set retail prices for the handsets to the subscribers. We then recover the margins for handset manufacturers and service providers, which will be used for our counterfactual analysis. ${ }^{17}$

We start from a scenario in which only handset (retail and wholesale) prices are decision variables given service prices. The carrier maximizes its total profits by choosing the optimal retail prices for handsets given monthly service fees.

$$
\max _{\substack{p_{j k}^{H} \\ j k}} \pi_{k}=\sum_{j \in J_{k}}\left[\left(p_{j k}^{H}-w_{j k}+r_{j k}^{S}\right) s_{j k}\left(p^{H}\right)\right]
$$

$J_{k}$ is the set of product sold by service provider $k, w_{j k}$ is the wholesale price for product $j, r_{j k}^{S}$ is the margin that the carrier receives on monthly service fees, and $s_{j k}(p)$ is the share of

\footnotetext{
$\overline{17}$ The specific terms of vertical contracts between handset manufacturers and service providers are complex and unobserved. Alternatively, a bargaining model between the contracting parties might be a reasonable approximation, e.g., Sinkinson [21] assumes that the joint surplus of the contracting parties is a determinant of market structure.
}

product-service bundle $j k$. The first order conditions for the handset prices, assuming a pure strategy Nash-equilibrium in prices, are

$s_{j k}+\sum_{m \in J_{k}}\left[\left(p_{m k}^{H}-w_{m k}+r_{m k}^{S}\right) \frac{\partial s_{m k}}{\partial p_{j k}^{H}}\right]=0$

Each handset manufacturer maximizes its profit by choosing the wholesale prices for its handsets, knowing how service providers set retail prices according to Eq. (2). The manufacturer's profit function is

$$
\pi_{w}=\sum_{j \in M_{w}} \sum_{k}\left(w_{j k}-c_{j k}\right) s_{j k}
$$

$M_{w}$ is the set of handsets produced by manufacturer $w$. The first order conditions are:

$s_{j k}+\sum_{j \in M_{w}} \sum_{k}\left(w_{j k}-c_{j k}\right) \frac{\partial s_{j k}}{\partial w_{j k}}=0$

As in Villas-Boas [25], we obtain the following vector expression for service providers' implied price-cost margins and manufacturers' wholesale price-cost margins respectively:

$$
\begin{gathered}
p^{H}-w+r^{S}=-\left(T_{r} * \Delta_{r}\right)^{-1} s\left(p^{H}\right) \\
w-c=-\left(T_{w} * \Delta_{w}\right)^{-1} s\left(p^{H}\right)
\end{gathered}
$$

$T_{w}$ is a ownership matrix for manufacturers, and $T_{y}$ is a ownership matrix for service providers. In particular, element $(i, j)$ in $T_{w}$ equals to one if a manufacturer sells both products $i$ and $j$, and zero otherwise. Similarly, element $(i, j)$ in $T_{r}$ equals to one if the service provider sells both products $i$ and $j$, and zero otherwise. $\Delta_{r}$ represents how demand responds to changes in retail prices of handsets, with element $(i, j)$ defined as $\frac{\partial s_{i}}{\partial p_{j}^{H}}$. $\Delta_{w}$ describes how demand responds to changes in wholesale prices of handsets, with element $(i, j)$ defined as $\frac{\partial s_{i}}{\partial w_{j}}{ }^{18}$

Note that the above two equations allow us to calculate the wholesale margins and retail margins. Because we do not have direct observations on $c, w$ or $r^{S}$, we are not able to identify them separately. However, such a separation is not critical for predicting retail prices - shifting $c, w$ and $r^{S}$ by a constant while preserving the margins will lead to the same retail

\footnotetext{
${ }^{18}$ The details on the calculation of these matrices are provided by VillasBoas[25].
} 
prices. Therefore it is sufficient to recover the wholesale and retail margins to perform our counterfactual analysis.

\section{Results}

We report the estimation results from three alternative models: (1) a logit model with no control for price endogeneity; (2) a logit model with control for price endogeneity; and (3) the proposed random coefficients logit model.

For comparison, results for models (1) and (2) are both reported in Table 7. We can see that after controlling for price endogeneity, consumers appear to be more sensitive to handset prices. Estimation results for model (3) are provided in Table $8 .{ }^{19}$ First, brand intercepts for top handset brands and for major service providers are reported. The values of these intercepts reflect the relative attractiveness of different brands, after accounting for other effects in the model. We find that Apple and BlackBerry enjoyed the highest preferences among all handset makers, which is consistent with the popularity of the iPhone and BlackBerry handsets. Among the major wireless carriers, Verizon and AT\&T appear to be more attractive than Sprint and T-Mobile on average.

Table 8 also shows that the parameters of most product features are of the expected sign and significant. Having features such as touch screen and GPS positively affect the consumers' mean utility for a handset. Smartphone and Contract are defined as dummy variables indicating a smartphone and a two-year contract respectively. It is interesting to observe that the parameter estimate for the contract subscriptions is negative. Intuitively, a consumer does not prefer to be locked in a two year contract, hence a service provider generally provides a price discount for handset to attract potential service subscribers. Smartphones are more attractive than regular phones after controlling for prices and product characteristics. From the interaction effect of technology attitude and smartphone, we find that consumers who are more technology proficient are more likely to subscribe to a smartphone service. Naturally, a stronger signal increases the utility of wireless service.

Next, we turn to the effects of prices on consumers' purchase decisions. In Eq. (1), we allow the price effects to be individual specific. In the estimation, we make these price effects specific to different income levels. The results suggest that lower-income individuals are more price sensitive than higher-income ones. According to the price coefficients, consumers are more sensitive to the monthly service price than the handset price, which is not surprising given that consumers have to sign a two-year contract and pay the monthly service fee for 24 months.

\footnotetext{
${ }^{19}$ While not reported here, the regression of prices on exogenous and instrumental variables yielded an $R^{2}$ of 0.72 .
}

Table 7 Parameter estimates (simple logit)

\begin{tabular}{|c|c|c|c|c|}
\hline \multirow[t]{2}{*}{ Variable } & \multicolumn{2}{|l|}{ Model (1) } & \multicolumn{2}{|l|}{ Model (2) } \\
\hline & estimate & $\begin{array}{l}\text { Std. } \\
\text { err. }\end{array}$ & estimate & $\begin{array}{l}\text { Std. } \\
\text { err. }\end{array}$ \\
\hline \multicolumn{5}{|l|}{ Brand intercepts for handsets } \\
\hline Apple & 0.6030 & 0.1554 & 0.8414 & 0.1592 \\
\hline BlackBerry & 0.5308 & 0.0900 & 1.064 & 0.0951 \\
\hline HTC & -1.1192 & 0.1964 & -1.0851 & 0.2065 \\
\hline LG & -0.0441 & 0.0490 & -0.0053 & 0.0484 \\
\hline Motorola & -0.2429 & 0.0504 & -0.0675 & 0.0509 \\
\hline Nokia & -0.6623 & 0.0576 & -0.6704 & 0.0573 \\
\hline Sanyo & -1.8323 & 0.1045 & -1.878 & 0.1056 \\
\hline Sony & -1.8720 & 0.0920 & -1.9486 & 0.0933 \\
\hline Palm & -0.6635 & 0.1556 & -0.7183 & 0.1564 \\
\hline Samsung & -0.6371 & 0.0518 & -0.6692 & 0.0514 \\
\hline \multicolumn{5}{|l|}{ Brand intercepts for carriers } \\
\hline AT\&T & 1.0295 & 0.0562 & 1.0393 & 0.0561 \\
\hline Sprint & -0.3363 & 0.0759 & -0.3021 & 0.076 \\
\hline T-Mobile & 0.1556 & 0.0726 & 0.0901 & 0.0731 \\
\hline Verizon & 0.9628 & 0.0577 & 0.9551 & 0.0578 \\
\hline \multicolumn{5}{|l|}{ Features } \\
\hline Touch screen & 0.5050 & 0.1098 & 0.7178 & 0.1084 \\
\hline GPS & 0.9852 & 0.0797 & 0.8913 & 0.0795 \\
\hline Smartphone & 1.2960 & 0.1908 & 1.1881 & 0.1822 \\
\hline Tech $*$ smartphone & 0.8338 & 0.0740 & 0.8286 & 0.0744 \\
\hline Contract & -1.0729 & 0.2221 & -1.1273 & 0.2254 \\
\hline Signal strength & 0.0774 & 0.0341 & 0.0926 & 0.0341 \\
\hline \multicolumn{5}{|l|}{ Price coefficients for handsets } \\
\hline Income group $1(<\$ 40,000)$ & -0.0146 & 0.0007 & -0.0178 & 0.0008 \\
\hline $\begin{array}{l}\text { Income group } 2 \\
\quad(\$ 40,000 \sim \$ 90,000)\end{array}$ & -0.0138 & 0.0006 & -0.0172 & 0.0006 \\
\hline Income group $3(>\$ 90000)$ & -0.0113 & 0.0007 & -0.0149 & 0.0009 \\
\hline \multicolumn{5}{|l|}{ Price coefficients for carriers } \\
\hline Income group $1(<\$ 40,000)$ & -0.0757 & 0.0058 & -0.0732 & 0.0058 \\
\hline $\begin{array}{l}\text { Income group } 2 \\
\quad(\$ 40,000 \sim \$ 90,000)\end{array}$ & -0.0633 & 0.0057 & -0.0603 & 0.0057 \\
\hline Income group 3 (>\$90000) & -0.0625 & 0.0057 & -0.0593 & 0.0058 \\
\hline \multicolumn{5}{|l|}{ State dependence } \\
\hline Service & 2.3749 & 0.0315 & 2.3839 & 0.0315 \\
\hline Phone & 0.5657 & 0.0339 & 0.5247 & 0.0341 \\
\hline Control factor & & & 0.0090 & 0.0005 \\
\hline Log likelihood & $-20,696$ & & $-20,567$ & \\
\hline \# of observations & 7526 & & 7526 & \\
\hline
\end{tabular}

We now calculate the average price elasticity of demand for handsets. For each household, we calculate price elasticity as the expected percentage change in the purchase probability of a handset relative to one percentage change in the handset price. We find that the average price elasticity for handsets is -1.77 across all smartphones. The price elasticity of iPhone is 
Table 8 Parameter estimates (random coefficients logit)

\begin{tabular}{|c|c|c|}
\hline Variable & Estimate & Std. err \\
\hline \multicolumn{3}{|l|}{ Brand intercepts for handsets } \\
\hline Apple & 0.6992 & 0.1554 \\
\hline BlackBerry & 0.7424 & 0.0974 \\
\hline HTC & -1.4024 & 0.2028 \\
\hline LG & -0.051 & 0.049 \\
\hline Motorola & -0.0608 & 0.0516 \\
\hline Nokia & -0.6744 & 0.0574 \\
\hline Sanyo & -1.9407 & 0.1074 \\
\hline Sony & -2.0212 & 0.095 \\
\hline Palm & -1.605 & 0.1682 \\
\hline Samsung & -0.6842 & 0.0517 \\
\hline \multicolumn{3}{|l|}{ Brand intercepts for carriers } \\
\hline AT\&T & 1.1100 & 0.0641 \\
\hline Sprint & -0.1379 & 0.1341 \\
\hline T-Mobile & -0.3001 & 0.2274 \\
\hline Verizon & 0.8003 & 0.0711 \\
\hline \multicolumn{3}{|l|}{ Features } \\
\hline Touch screen & 1.0194 & 0.1056 \\
\hline GPS & 0.8027 & 0.0850 \\
\hline Smartphone & 0.7694 & 0.1833 \\
\hline Tech * smartphone & 0.8303 & 0.0765 \\
\hline Contract & -1.3149 & 0.2910 \\
\hline Signal Strength & 0.0746 & 0.0344 \\
\hline \multicolumn{3}{|l|}{ Price coefficients for handsets } \\
\hline Income group $1(<\$ 40,000)$ & -0.0183 & 0.0008 \\
\hline Income group $2(\$ 40,000 \sim \$ 90,000)$ & -0.0177 & 0.0006 \\
\hline Income group $3(>\$ 90000)$ & -0.0154 & 0.0007 \\
\hline \multicolumn{3}{|l|}{ Price coefficients for carrier } \\
\hline Income group $1(<\$ 40,000)$ & -0.0678 & 0.0075 \\
\hline Income group $2(\$ 40,000 \sim \$ 90,000)$ & -0.0550 & 0.0074 \\
\hline Income group $3(>\$ 90000)$ & -0.0543 & 0.0075 \\
\hline \multicolumn{3}{|l|}{ State dependence } \\
\hline Service & 2.4411 & 0.0328 \\
\hline Phone & 0.5305 & 0.0345 \\
\hline Control factor & 0.0092 & 0.0006 \\
\hline \multicolumn{3}{|l|}{ Covariance matrix } \\
\hline$\sigma 11$ & 0.6836 & 0.1820 \\
\hline$\sigma 12$ & 0.0288 & 0.0404 \\
\hline$\sigma 13$ & 0.0189 & 0.0602 \\
\hline$\sigma 14$ & 0.1450 & 0.1512 \\
\hline o15 & 0.2643 & 0.0820 \\
\hline$\sigma 22$ & 0.1530 & 0.0528 \\
\hline$\sigma 33$ & 0.2157 & 0.1259 \\
\hline$\sigma 44$ & 0.7678 & 0.3704 \\
\hline o55 & 0.1935 & 0.0816 \\
\hline Log likelihood & $-20,474$ & \\
\hline \# of observations & 7526 & \\
\hline
\end{tabular}

relatively high with the magnitude of $-3.46 .{ }^{20}$ For the handset with a price of zero, we calculate the semi price elasticity. For example, if the price of the free handset increases to $\$ 10$, then the market share will decrease by $15.6 \%$ on average.

We find strong state dependence in consumers' choices of handset brands and service providers, which suggests a strong tendency for consumers to stay with their current handset brands and with their current service providers. In terms of the magnitude, the state dependence effect in service providers is much larger than that in handset brands, possibly due to more competition in the handset market.

From the estimates for the covariance matrix for $v_{i}$, we observe that there is less heterogeneity in consumer preferences for service providers than for smartphones. In addition, we find significant positive preference correlation between smartphones and Verizon.

From the supply side model, we can solve for the retail margins for service providers and the wholesale margins for handset manufacturers. We then calculate the average margins across all handset-carrier combinations. On average, a carrier's margin is $9.3 \%$ and a handset manufacturer's margin is $5.8 \%$ of the total revenue including monthly service fees from a two-year contract and handset retail prices. ${ }^{21}$

\section{Counterfactual Analysis}

Our research objective is to measure the impact of iPhone's exclusive arrangement on consumer welfare. This requires us to conduct a counterfactual analysis to uncover what would have happened if the iPhone were not under an exclusive arrangement and hence available to other wireless carriers as well. We examine two scenarios: (1) if iPhones are available to Verizon in addition to AT\&T; and (2) if iPhones are available to all wireless carriers.

First we assume away any competitive responses and hold all retail prices constant in the market. For other carriers who could also offer iPhone in a counterfactual scenario, we assume the same retail price of $\$ 199$ on the iPhone. The predicted market shares are reported in Table 9. If both AT\&T and Verizon carried iPhones, Apple's market share would have been $2.25 \%, 0.9 \%$ higher than the observed $1.35 \%$ under the exclusive arrangement. If all carriers could offer iPhones, Apple's market share would have further increased to $3.48 \%$.

To evaluate the welfare loss resulting from the exclusive arrangement between Apple and AT\&T, we calculate, following Small and Rosen [31], the compensating variation as a measure of welfare change. Using the estimates of our demand

\footnotetext{
${ }^{20}$ Scott Cunningham from CoreEconomics used a different approach to calculate elasticity of demand for the iPhone, and found an elasticity of -3.37 for the iPhone.

${ }^{21}$ Dedrick et al. [37] also finds that carriers capture higher gross profits from each handset than the handset makers.
} 
Table 9 Predicted market shares without price adjustments

\begin{tabular}{llll}
\hline Carrier & \multicolumn{2}{l}{ iPhone for } & \\
\cline { 2 - 4 } & AT\&T only & AT\&T + Verizon & All carriers \\
\hline AT\&T & $1.35 \%$ & $1.34 \%$ & $1.33 \%$ \\
T-Mobile & & & $0.28 \%$ \\
Sprint & & \multirow{2}{*}{$0.91 \%$} & $0.23 \%$ \\
Verizon & & & $0.90 \%$ \\
Others & & $2.25 \%$ & $0.74 \%$ \\
Total & $1.35 \%$ & $3.48 \%$ \\
\hline
\end{tabular}

model, the average welfare loss from one consumer due to the exclusive contract is $\$ 1.08$ for each purchase occasion. Given that there were 300 million potential wireless subscribers and $70 \%$ subscribed to a two-year contract in the U.S. by the beginning of 2009, the aggregate welfare loss is estimated to be $\$ 210$ million per year, which is $0.14 \%$ of the $\$ 145$ billion in revenues for the U.S. wireless industry in 2008.

In the analysis above, we hold all retail prices constant and focus on the welfare loss due to the absence of a choice alternative. However, in a counterfactual market environment we would expect firms to adjust their prices in response to the different channel structure. Therefore it is important to model the strategic interactions between firms and to account for competitive responses. As mentioned before, we assume that handset makers and wireless carriers follow a Stackelberg leader-follower pricing game, in which handset makers set wholesale prices first, whereas wireless carriers set retail prices accordingly.

To make the model tractable we assume that wireless carriers would have kept the current monthly service fees while adjusting handset prices in these counterfactual situations. The proposed model follows Villas-Boas [25], Chen et al. [32], Chu et al. [33] and Asker [26]. By assuming a Stackelberg leader-follower game between handset manufacturers and wireless carriers, we are able, as shown previously, to back out the marginal costs for various handsets and then use these cost numbers to predict the retail prices in counterfactual market environments.

We first predict the retail prices of the iPhone from different carriers if it became available from both AT\&T and Verizon. ${ }^{22}$ The predicted prices and market share are reported in the second and third column of Table $10 .{ }^{23}$ In the fourth column, we report the predicted prices of iPhone if it became available from all carriers. We find a small change in AT\&T's

\footnotetext{
${ }^{22}$ Since we do not have the marginal costs of iPhone from other carriers, we assume that their marginal costs are the same as AT\&T's, which has been recovered from the supply side model.

${ }^{23}$ Verizon launched the iPhone 4 at a starting price of $\$ 199$ in February 2011. According to Localytics, a mobile app analytics firm, Verizon had 32 percent of the iPhone 4 market in July 2011 (http://www.localytics. com/blog/2011/verizon-powering-32-of-all-us-iphone-4s/).
}

Table 10 Predicted retail prices and market shares

\begin{tabular}{|c|c|c|c|c|}
\hline \multirow[t]{2}{*}{ Carrier } & \multicolumn{2}{|c|}{ iPhone for AT\&T \& Verizon } & \multicolumn{2}{|c|}{ iPhone for all carriers } \\
\hline & Predicted price & Market share & Predicted price & Market share \\
\hline AT\&T & $\$ 199.98$ & $1.31 \%$ & $\$ 199.13$ & $1.31 \%$ \\
\hline T-Mobile & & & $\$ 149.56$ & $0.63 \%$ \\
\hline Sprint & & & $\$ 145.75$ & $0.53 \%$ \\
\hline Verizon & $\$ 205.09$ & $0.83 \%$ & $\$ 205.19$ & $0.81 \%$ \\
\hline Others & & & $\$ 163.37$ & $1.31 \%$ \\
\hline Total & & $2.14 \%$ & & $4.59 \%$ \\
\hline
\end{tabular}

subsidized price of iPhone. The price from Verizon would have been slightly higher, but the smaller carriers would have offered much lower prices. We also find that under the new channel structure, AT\&T would have lowered its prices slightly for other handsets ${ }^{24}$ while its competitors would have increased prices for other handsets. The intuition is that AT\&T would have lost its relative advantage on product selection if iPhones were available from other carriers, and thus might have cut prices on other handsets to stay competitive. By contrast, with the iPhone, other carriers might have been less aggressive in their pricing of other handsets. Based on the predicted prices, we calculate market shares and welfare consequences. The market share for the iPhone would have been $4.59 \%$, higher than the $3.48 \%$ without accounting for price adjustments. The annual welfare loss is estimated to be $\$ 326$ million, ${ }^{25}$ again higher than the previous estimate primarily due to lower prices from smaller carriers. This seems like a small number given the overall revenue picture for the wireless industry.

\section{Conclusions}

In this paper we study the welfare consequences of the exclusive arrangement between Apple and AT\&T on iPhone. First we estimate consumer demand for wireless services including their choices in both handsets and wireless service providers. Our approach provides a framework to investigate the complex problem of understanding consumers' joint purchases in these closely related product categories. We then model the pricing decisions of handset makers and wireless carriers, in order to predict how they would have adjusted their prices in the counterfactual scenario that iPhone were not subject to an exclusive contract and thus available to all wireless carriers. Our results suggest that the annual welfare loss resulting from the exclusivity agreement for iPhones is about $\$ 326$ million, of which $\$ 210$ million is due to restricting consumers' choice

\footnotetext{
${ }^{24}$ The price drops $\$ 0.41$ on average.

${ }^{25}$ The $95 \%$ confidence interval for the annual welfare gain is $(\$ 314$ million, \$338 million).
} 
sets, and the rest due to firms' price adjustments. However, we acknowledge that our estimates are based on the assumptions we made for tractability in model estimation. In Table 11, We summarize the assumptions made for tractability in estimation and speculate how a violation of the assumptions will alter the estimate of welfare gain. For example, we do not account for the effects of firms' advertising decisions. If these effects are additive in the utility specification and if they do not change with respect to exclusivity, their omission should not affect our welfare estimates given the use of compensating variation. On the other hand, if exclusivity gives stronger incentive to advertise, it may help the diffusion of iPhone and we could overstate the welfare loss due to exclusivity.

Several limitations of our study leave opportunities for future research. First, when iPhone was first launched some consumers might decide to postpone their purchases in expectation of a lower price or more apps for iPhone in the future. In this study, we do not incorporate consumers' forward-looking

Table 11 Simplifying assumptions and the impact on welfare analysis

Simplifying assumptions
We do not model consumer
forward-looking behavior - when
iPhone was first launched some
consumers might decide to post-
pone their purchases in expecta-
tion of a lower price or more
apps for iPhone in the future.

Impact on the welfare analysis

Although these consumers may purchase in future periods but in our static demand estimates they are treated the same as those who are not interested in the iPhone. If we were to conduct long-term welfare analysis, using our demand estimates we could understate the welfare loss due to exclusivity. However, the impact on our short-term welfare analysis might be limited.

We do not model innovations - ex- If indeed exclusivity leads to more clusivity may encourage innovations by allowing risk sharing between handset makers and wireless carriers.

We assume that handset manufacturers and service providers follow a Stackelberg game on handset pricing.

We do not account for the effects of advertising decisions. innovations, it will induce longterm welfare gains to consumers. Given that in this study we focus on the direct welfare loss due to exclusivity, again the impact might be limited.

The impact on our welfare estimates is ambiguous without a formal comparison with alternative game structures.

If these effects are additive in the utility specification and if they behavior. This assumption may bias our estimates for the welfare changes with exclusive arrangements.

Second, we examine the welfare loss to consumers due to the fact that exclusive arrangements restrict consumer choices. However, major wireless carriers argue that exclusive arrangements allow risk sharing between handset makers and wireless carriers, and hence encourage innovations. This could induce long-term welfare gains to consumers. In this study we abstract away from this aspect of the welfare consequence, and focus on the direct welfare loss due to exclusivity. It may be fruitful for future studies to take a more complete view and examine the long-term effect by taking into account innovations.Finally, our counterfactual analysis is dependent on several assumptions on the supply-side model. Because we do not have detailed information on production costs of handsets and service costs incurred by service providers, we have to make assumptions on the pricing game played between firms, and rely on the structure of our supply-side model to identify the marginal profits for each player in the game. We acknowledge that we have only explored a small subset of potential interactions on handset pricing decisions among the players. Other game structures, such as bargaining among the manufacturers and service providers and the service price competition among service providers have not been explored. Again we also ignore possible dynamic considerations on the supply side. Given better information on firms' cost structure, we could relax some of the relatively strong assumptions we have to rely on.

In summary, our study is the first step to empirically analyze the issue of exclusive arrangements. We estimate the direct welfare loss resulting from the exclusivity agreement between Apple and AT\&T on iPhone, and seek to provide empirical evidence for policy makers. There are several limitations in our study, which we believe to be important and worthwhile for future research to investigate.

\section{References} do not change with respect to exclusivity, their omission should not affect our welfare estimates given the use of compensating variation. On the other hand, if exclusivity gives stronger incentive to advertise, it may help the diffusion of iPhone and we could overstate the welfare loss due to exclusivity.
1. Raice S, Kane YI (2011) Verizon unwraps iPhone. Wall Street J 12: 2011

2. Kharif O, Burrows $P$ (2008) On the train of the missing iPhones. Businessweek 11:26-28

3. Schatz A (2009) "FCC to Review Exclusive Deals that Lock up Hot Cellphones," Wall Street Journal, June 19, 2009, page B3

4. Ford GS, Koutsky TM, Spiwak LJ (2008) Consumers and wireless carterfone: an economic perspective. Phoenix Center Policy Bull 20: $1-11$

5. Hoeker MT (2008) From caterfone to the iPhone: consumer choice in the wireless telecommunications market place. Comm Law Conspectus: J Commun Law Policy 17:187-231

6. Hahn R, Singer HJ (2010) Why the iPhone Won't Last Forever and What the Government Should Do to Promote its Successor. J Telecomm High Tech 8:313-350 
7. Subramanian U, Raju JS, and Zhang ZJ (2008) "Exclusive Tie-Ups for Handsets in the Cellular Industry," working paper

8. Entner R (2009) "Is Handset Exclusivity Really the Wireless Issue of the Day?" Nielsen Wire, August 27

9. Baker CA. (2007) "Breaking Up Is Hard to Do:Consumer Switching Costs in the U.S.Marketplace for Wireless Telephone Service," working paper

10. Hermalin BE and Katz ML (2010) "Product Differentiation Through Exclusivity," working paper

11. Rooney JE (2009) "Written Statement of Mr. John E. Rooney, President and Chief Executive Officer before the U.S. Senate Committee on Commerce, Science and Transportation"

12. Hausman J (1999) Cellular telephone, New products and the CPI. J Bus Econ Stat 17(2):188-194

13. Iimi A (2005) Estimating demand for cellular phone services in Japan. Telecommun Policy 29:3-23

14. Bajari P, Fox JT, Ryan SP (2008) Evaluating wireless carrier consolidation using semiparametric demand estimation. Quant Mark Econ 6(4):299-338

15. Lambrecht A, Seim K, Skiera B (2007) Does uncertainty matter? consumer behavior under three-part tariffs. Market Sci 26(5):698710

16. Kim J (2006) "Consumers' Dynamic Switching Decisions in the Cellular Service Industry,” working paper

17. Grzybowski L and Pereira P (2009) "Subscription Choices and Switching Costs in Mobile Telephony," working paper

18. Jain DC, Muller E, Vilcassim NJ (1999) Pricing patterns of cellular phones and phonecalls: a segment-level analysis. Manag Sci 45(2): 131-141

19. Aribarg A, Foutz NZ (2009) Category-based screening in choice of complementary products. J Market Res 46(4):518-530

20. Liu H, Chintagunta PK, Zhu T (2010) Complementarities and the demand for home broadband internet services. Market Sci 29(4): 701-720

21. Sinkinson M (2011) "Pricing and Entry Incentives with Exclusive Contracts: Evidence from Smartphones," working paper
22. Lafontaine F, and Slate M (2008) "Exclusive Contracts and Vertical Restraints: Empirical Evidence and Public Policy," in Handbook of Antitrust Economics, Paolo Buccirossi Ed., MIT Press

23. Besanko D, Dube JP, Gupta S (2003) Competitive price discrimination strategies in a vertical channel using aggregate retail data. Manag Sci 49:1121-1138

24. Petrin A. and K. Train, "A Control Function approach to Endogeneity in Consumer Choice Models," Journal of Marketing Research, 47 (1), 3-13

25. Villas-Boas SB (2007) Vertical relationships between manufacturers and retailers: inference with limited data. Rev Econ Stud 74(2):625-652

26. Asker J. (2005) "Diagnosing Foreclosure due to Exclusive Dealing," working paper

27. Brenkers R, Vervoven F (2006) Liberalizing a distribution system: the european Car market. J Eur Econ Assoc 4(1):216-251

28. Albuquerque P, Bronnenberg BJ (2012) Measuring the impact of negative demand shocks on Car dealer networks. Market Sci 31(1): 4-23

29. Petrin A (2002) Quantifying the benefits of New products: the case of the minivan. J Polit Econ 110(4):705-729

30. Sun Y. (2011). "From a Battle of Devices To a War of Platforms: An Empirical Analysis of the Smartphone Market," working paper

31. Small KA, Rosen HS (1981) Appied welfare economics with discrete choice models. Econometrica 49(1):105-130

32. Chen X, John G, Narasimhan O (2007) Assessing the consequences of a channel switch. Marketing Sci 27(3):398-416

33. Chu J, Chintagunta PK, Vilcassim NJ (2007) Assessing the economic value of distribution channels: an application to the personal computer industry. J Mark Res 44(1):29-41

34. Berry S, Levinsohn J, Pakes A (1995) Automobile prices in market equilibrium. Econometrica 63(4):841-889

35. Sudhir K (2001) Competitive pricing behavior in the auto market: a structural analysis. Market Sci 20(1):42-60

36. Sharma A (2009) "Telecoms Face Antitrust Threat," by Amol Sharma, Wall Street Journal, July 7, 2009, page A1

37. Dedrick JK, Kraemer L, Linden G (2010) "The Distribution of Value in the Mobile Phone Supply Chain," working paper 